\title{
Mecanismo de fonte dos tremores desencadeados por reservatório na UHE Irapé, Minas Gerais
}

Guilherme Ferreira da Silva CPRM/UnB*, Cristiano Naibert Chimpliganond SIS/UnB, Mônica Giannoccaro Von Huelsen SIS/UnB, José Oswaldo de Araújo Filho UnB, George Sand França SIS/UnB, Lucas Vieira Barros SIS/UnB.

Copyright 2014, SBGf - Sociedade Brasileira de Geofísica

Este texto foi preparado para a apresentação no VI Simpósio Brasileiro de Geofísica, Porto Alegre, 14 a 16 de outubro de 2014. Seu conteúdo foi revisado pelo Comite Técnico do material para propósitos comerciais sem prévia autorização da SBGf.

\section{Resumo}

Inaugurada em 2006, a Usina Hidrelétrica de Irapé possui a mais alta barragem do país, com 208 metros. Esta vem sendo monitorada pelo Observatório Sismológico da Universidade de Brasília desde o começo do enchimento do seu reservatório. Apresentando sismicidade causada pelo aumento da tensão crustal logo após o início do represamento, a Sismicidade Desencadeada por Reservatório da UHE de Irapé permanece como objeto de estudo importante para o entendimento deste fenômeno. O presente trabalho se propõe a estudar a sismicidade registrada de janeiro a maio de 2006, assim como a caracterizar a geologia ao redor da UHE de Irapé com o intuito de identificar e descrever as estruturas que permitam compreender melhor os eventos sísmicos.

\section{Introdução}

A Sismicidade Desencadeada por Reservatório (SDR) é um fenômeno com influência antropogênica registrado concomitantemente e/ou posteriormente ao preenchimento de um reservatório de água (geralmente Usina Hidrelétrica - UHE), onde anteriormente havia ou não o registro de atividade sísmica. Este fenômeno, ainda que seja pouco compreendido, pode ser encarado como uma resposta da crosta rasa às mudanças no campo de tensão em que se encontra submetida. Os eventos de SDR podem apresentar variação de intensidade, frequência e distribuição dos tremores de acordo com o terreno onde a UHE foi implantada. A ocorrência não pode ser prevista, embora estejam associados preferencialmente aos grandes reservatórios e ensaios semi-quantitativos de mecânica das rochas e o conhecimento geológico possam fornecer informações para este fim.

Este trabalho tem a intenção de apresentar detalhadamente os procedimentos e os resultados encontrados no processamento dos dados de sismologia dos eventos sísmicos registrados na região da Usina Hidrelétrica de Irapé, dentre os anos de 2006 e 2007. Nele são apresentados a análise inicial, a evolução espaço-temporal dos sismos e o método utilizado para conhecer alguns parâmetros da fonte sísmica.

O monitoramento sismológico da área de influência da UHE de Irapé teve início ainda durante a fase de obras, no dia 17 de setembro de 2003, com a instalação da estação IRP1. Esta estação operou até o dia 17 de maio de 2005. Pelo período de dois meses consecutivos ao enchimento do reservatório as estações IRP1, IRP2, IRP3 e IRP4 funcionaram total ou parcialmente, não havendo, nesta época, registro de sismicidade em todas as estações concomitantemente. A série de eventos selecionados para este trabalho compõem o período de 07 de janeiro a 17 de maio de 2006, abrangendo o principal evento de SDR registrado, assim como suas réplicas e seus precursores.

Durante este período de tempo, foram escolhidos somente os eventos registrados pelas três estações operantes, devido à maior confiabilidade na localização dos mesmos. Por este motivo, é apresentado aqui a configuração das estações IRP2, IRP3 e IRP4 (Figura 1). Todas as estações foram instaladas sobre leito rochoso, com exceção da estação IRP4, instalada sobre um matacão, o que refletiria negativamente na qualidade do sinal captado.

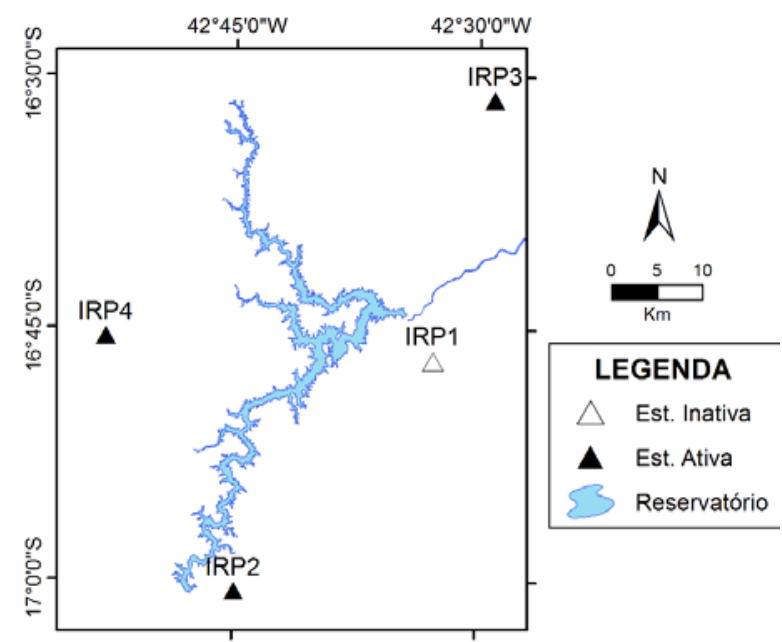

Figura 1: Arranjo das estações ao redor da UHE Irapé. A estação IRP1 estava desativada durante o período analisado por este trabalho.

O sensor utilizado nestas três estações foi um sismômetro de período curto modelo Guralp 40T-1, acoplado a um digitalizador Reftek (100 amostragens por segundo), sendo ambos alimentados por bateria e painel solar instalado fora do abrigo (Figura 19).

A localização das estações foi arranjada de modo a fornecer uma boa distribuição azimutal, porém, com a inoperância da estação IRP1, toda a região leste do eixo da barragem ficou descoberta. As distâncias entre as estações operantes e o eixo da barragem variam de 23 a 35 km, sendo a estação IRP2 a mais distante.

\section{Metodologia}

Informações confiáveis sobre as características das fontes sísmicas são os quesitos mais importantes para se começar a compreender os processos que causam os terremotos, quer sejam naturais ou induzidos. Uma das ferramentas utilizadas para se obter estas 
informações (Momento Tensor e solução de mecanismo focal) é a inversão da forma de onda no domínio do tempo (ZAHRADNíK et al., 2008).

Mesmo com porções específicas de um sismograma, é possível obter informações consideráveis sobre o evento sísmico (SOKOS \& ZAHRADNÍK, 2008), porém um estudo que considere na sua modelagem todo o sinal atribuído consegue melhores respostas para as perguntas em questão, levando-se em conta fatores de complexidade indubitada, como a heterogeneidade da crosta terrestre e a relação sinal e ruído, dentre outros.

A rotina do ISOLA leva em consideração o modelo crustal de propagação das ondas sísmicas (fornecido pelo intérprete) e as informações dos sistemas sismográficos (resposta em frequência de sensor e digitalizador) para calcular a função de Green (BOUCHON, 1981). Para desenvolver estas etapas, é preciso pré-processar o sinal sísmico, de forma a atenuar sua complexidade para tornar a modelagem mais realista e possível, tendo em vista a dificuldade de modelar sinais com fases de alta frequência (SOKOS \& ZAHRADNÍK, 2013).

O modelo crustal (Figura 2) utilizado para a inversão de localização epicentral utilizando o Hypo71 e visando a obtenção da solução de mecanismo focal (utilizando o ISOLA) foi baseado em informações obtidas através dos métodos geofísicos potenciais apresentados por Silva (2014), como por exemplo, a profundidade de contato do embasamento com rochas supracrustais, além de informação geológica prévia. Nele, é considerado um pacote de rochas metassedimentares de baixa velocidade constituído por metassedimentos do Grupo Macaúbas Distal, sobreposto a uma camada de quartzitos do Supergrupo Espinhaço e Formação Rio Peixe Bravo. As camadas de maior profundidade, correspondentes à transição da crosta superior e inferior (descontinuidade de Conrad, "granulitização da crosta"; WEVER, 1989) foram baseadas no modelo crustal genérico gerado pelo trabalho de Assumpção et al. (2012).

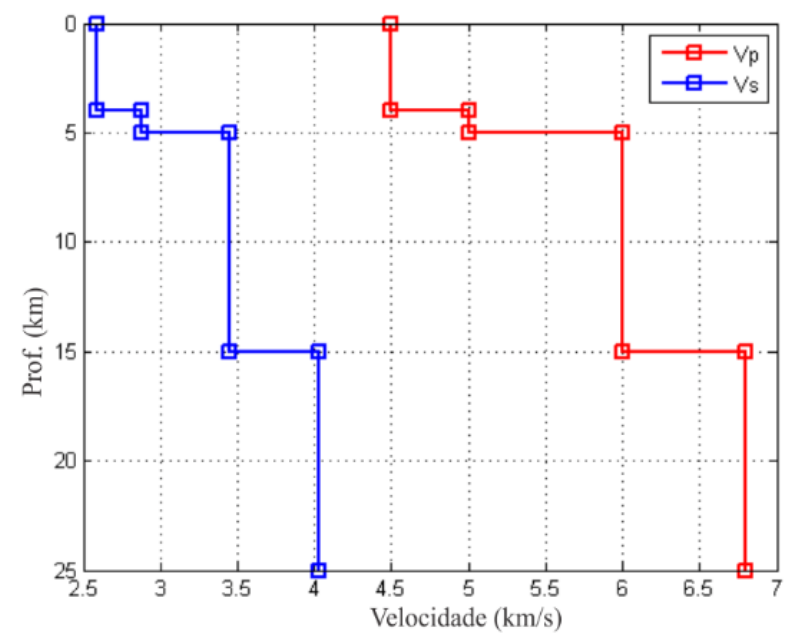

Figura 2: Modelo crustal construído para a área de estudo

A rotina utilizada neste trabalho consiste na inversão ponto-a-ponto da forma de onda no domínio do tempo, trabalhada em linguagem FORTRAN e expressão gráfica do Matlab denominada ISOLA e desenvolvida por Sokos \& Zahradník (2008).

\section{Resultados}

Uma vez calculada a função de Green, o programa ISOLA pode gerar a forma de onda sintética baseada na faixa de frequência colocada, que também varia de acordo com as heterogeneidades laterais do meio. A faixa de frequência utilizada para a inversão da forma de onda dos sinais do evento principal (discutido anteriormente) é de 0,9 a 1,4 Hz.

Após esta etapa, foi calculada a variância entre os dois sinais e posteriormente o grau de correlação médio, que depende do ajuste entre o sinal sintético e o sinal medido. Devido às dificuldades atribuídas a uma baixa razão sinal/ruído e à localização da estação IRP4 (instalada sobre um bloco de rocha solto), o sismograma obtido pela mesma não possui um bom ajuste para os parâmetros citados acima. Visando obter um resultado de melhor qualidade (uma vez que neste caso estaria se modelando basicamente ruído e sinal de baixa qualidade) foi escolhido não levar em conta a estação IRP4 na inversão (Figura 3).

Embora a modelagem que desconsiderou a estação IRP4 tenha obtido um menor percen-tual de Double Couple, no resultado onde essa estação é desconsiderada os demais valores dos outros parâmetros mostram uma melhora considerável. A Tabela 1 resume os resultados encontrados para a inversão da forma de onda utilizando o sinal de 2 e 3 estações.

Tabela 1: Resumo dos resultados obtidos na inversão da forma de onda

\begin{tabular}{|c|c|c|}
\hline \hline Parâmetros & 2 Estações & 3 Estações \\
\hline \hline CORR. & 0,78 & 0,65 \\
\hline D.C. (\%) & 50,7 & 93,5 \\
\hline C.N. & 13,7 & 9,9 \\
\hline V.R. & 0,61 & 0,43 \\
\hline Prof. (km) & 1,0 & 1,5 \\
\hline Mw & 2,3 & 2,1 \\
\hline Geologia & Confere & Não confere \\
\hline Polaridade & Confere & Não confere \\
\hline \hline
\end{tabular}

CORR. Correlação da solução; D.C.(\%) Par acoplado, double couple; C.N. Número de condição; V.R. Redução de variância; $M_{W}$ Magnitude de momento sísmico; GEOLOGIA Direção média de falhas rúpteis; POLARIDADE Polaridade da onda $P$.

Com base no sinal sintético processado, a inversão da forma de onda gera algumas soluções de mecanismo focal possíveis, porém distintas entre si na posição, profundidade e no tempo. A solução de mecanismo focal adotada como saída principal do ISOLA é aquela que apresenta maior correlação entre o sinal sintético e o sinal registrado (Figura 4). Nota-se que, portanto, por mais que seja uma tentativa de modelagem inversa do problema para se chegar a uma solução viável, a coerência estatística deve sempre ser considerada. 


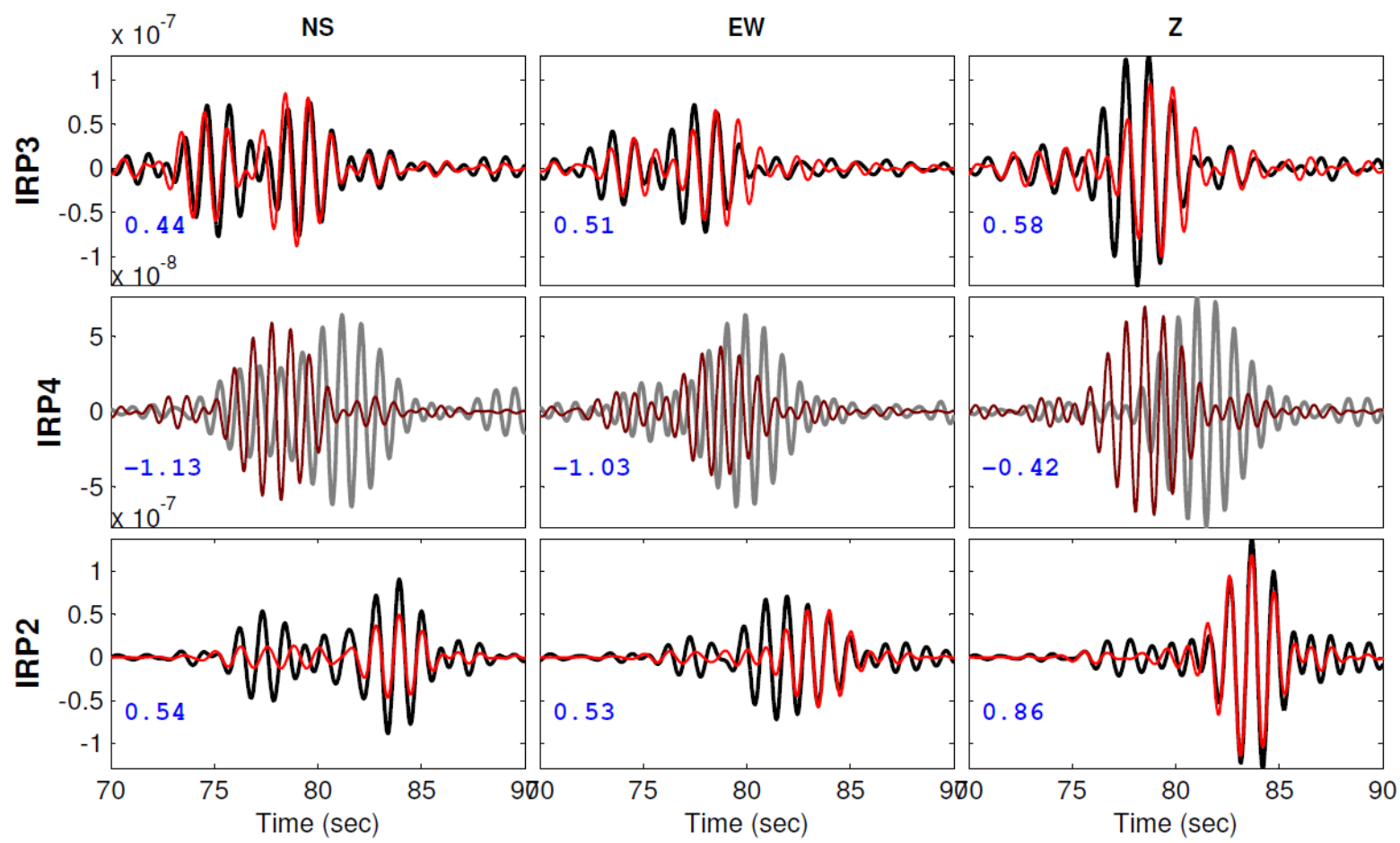

Figura 3: Gráfico de ajuste das curvas do sinal sintético (vermelho) e do sinal real (preto) no domínio do tempo. Os números azuis correspondem à correlação entre ambos, dentro de cada componente analisada. $O$ sinal de coloração acinzentada indica que a estação em questão não foi utilizada para a inversão.

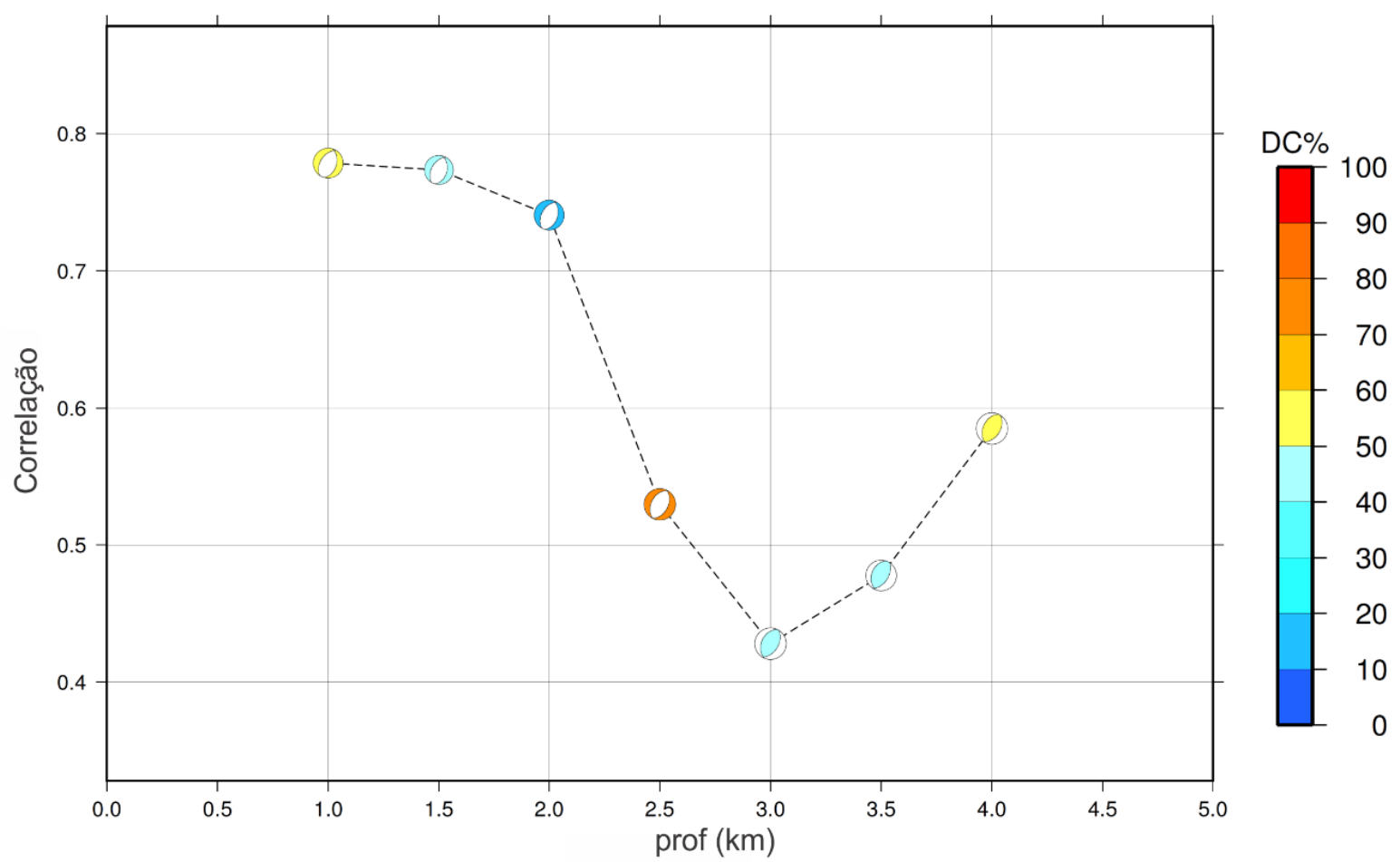

Figura 4: Gráfico de correlação da fonte sísmica pela profundidade. Os diagramas coloridos no interior do gráfico expressa as caracetrísticas do mecanismo focal descrito, e a coloração varia em função da porcentagem de $D C$. Entre os diagramas apresentados há grande coerência de atitude dos planos nodais, variando somente os parâmetros de $D C$ e de direção dos eixos de tensão. 


\section{Discussão e Conclusões}

Os planos nodais apresentados são fruto de uma média entre as diversas soluções encontradas (Figura $5 a)$, situadas em relação à variação da posição dos eixos de compressão $(P)$ e de tração $(T)$. É importante verificar se os planos nodais são coerentes em relação a toda informação possível de polaridade de onda $\mathrm{P}$, pois de tal modo tem-se maior confiança na veracidade das informações apresentadas (Figura 5b). De posse desta afirmação, verificou-se que o resultado encontrase compatível com o verificado nos sismogramas, com a simples ressalva de que a estação IRP2 encontra-se muito próxima a um plano nodal, o que faz com que a sua polaridade seja dúbia.

De acordo com o método de inversão do ISOLA, a fonte sísmica do evento principal de SDR da UHE de Irapé apresenta um mecanismo focal de falha normal, com direção média de planos nodais no sentido NE/SW, eixo de compressão verticalizado e eixo de tração horizontalizado (Figura 6). Tal resultado é coerente com o discutido no Capítulo 2, onde a região encontra-se em um domínio majoritariamente extensivo, ou o papel da tensão vertical adicionada pelo peso da coluna de água bruscamente incrementado tem uma função importante no desequilíbrio do campo de tensões da crosta rasa local, acarretando, por fim, no desencadeamento dos terremotos relacionados à barragem.

O diagrama de solução de mecanismo focal encontrado mostra dois planos nodais que são interpretados como possíveis falhas geradoras do principal evento sísmico. Estes planos, perpendiculares

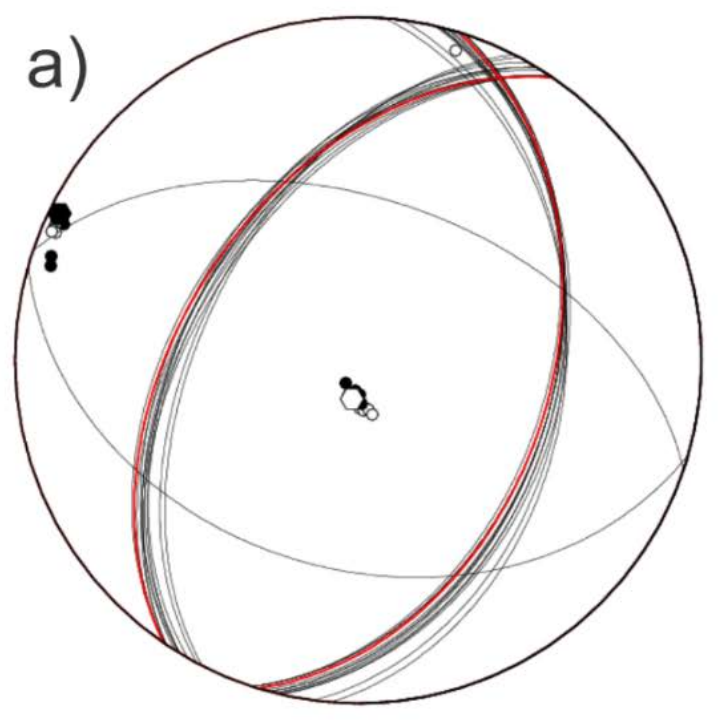

entre si, apresentam mergulhos em quadrantes opostos ( $2^{\circ}$ e $4^{\circ}$ quadrante) e direção próxima a N30E. $\mathrm{Em}$ todos os demais resultados encontrados, a tendência de estruturas na direção NE é evidente. As falhas rúpteis, tratadas nos estereogramas, consistem de planos de descontinuidades não "soldados" por veios de quartzo, que influenciaram a SDR neste caso, observando também a tendência linear da ocorrência dos epicentros.

Como o reservatório se encontra sobre uma região intensamente deformada pelo ciclo Brasiliano e por fases posteriores, levanta-se a suposição de que a estruturação geológica da crosta rasa local seja de maior importância nestes casos do que quando se trata de barragens construídas em regiões de geologia muito simples, como em regiões de bacias sedimentares profundas. É importante também compreender que os eventos de SDR tendem a ocorrer em profundidades relativamente rasas, portanto a presença de estruturas geológicas rasas influencia na dissipação da tensão adicionada; do mesmo modo que a ausência de tais estruturas poderia forçar a criação de novas falhas, se as condições geomecânicas forem favoráveis a tal condição devido aos valores de tensão

\section{Agradecimentos}

Os autores agradecem ao Ao CNPq pelo auxílio financeiro através do projeto de pesquisa 481178/20104, ao Observatório Sismológico, na pessoa do professor Lucas Vieira Barros, pelo apoio aos trabalhos de campo. Agradeço também a CEMIG, na pessoa do Eng. Alexandre Melo, pela concessão dos dados sismológicos e suporte quando necessário

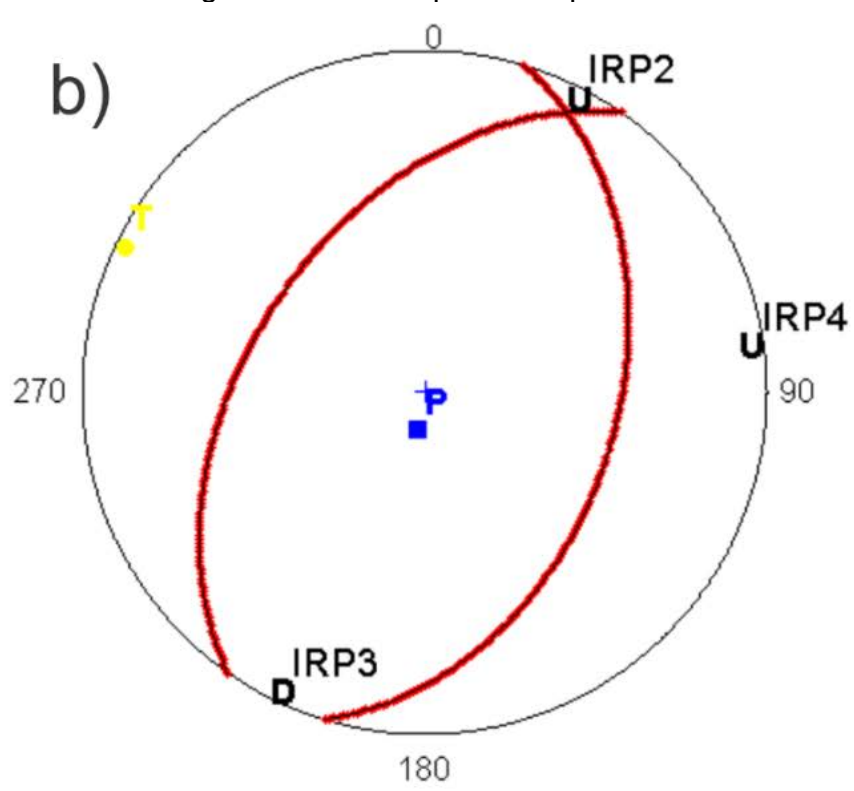

Figura 5: Diagramas de ajuste de planos nodais. a) Variação dos planos nodais da solução em função da posição dos eixos P e T. b) Verificação das polaridades de onda $P$ em função da sua posição em relação aos planos nodais e aos eixos de tensão. 


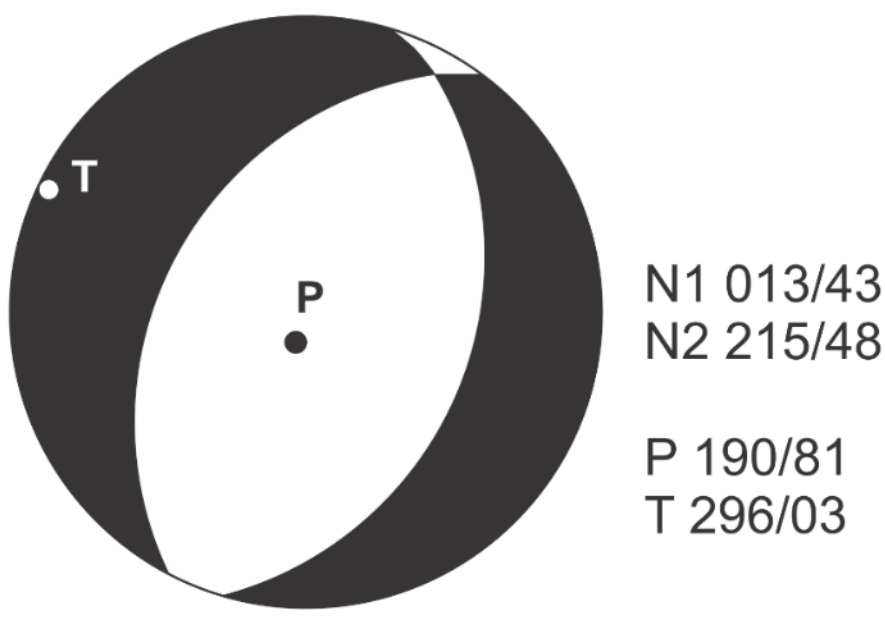

Figura 6: Diagrama de mecanismo focal encontrado através da inversão da forma de onda. Trata-se de um mecanismo focal majoritariamente extensivo e de eixo de compressão verticalizado. Os planos nodais alinham-se na direção NE/SW.

\section{Referências Bibliográficas}

BOUCHON, M. 1981. A simple method to calculate Green's functions for elastic layered me-dia. Bulletin of Seismological Society of America, vol 71, 959-971 p.

SILVA, G. F. Interpretação Geológica e Geofísica da área de influência da Usina Hidrelé-trica de Irapé, MG. 2014. Dissertação de Mestrado. Programa de Pós-graduação em Geociências Aplicadas. Instituto de Geociências, Universidade de Brasília, Brasília, 2014.

SOKOS, E. N. \& ZAHRADNÍK, J. 2008. ISOLA a Fortran code and a Matlab GUI to Perform multiple-point source inversion of seismic data, Computer \& Geosciencies, 34(8):967-977.

SOKOS, E. N.; \& ZAHRADNÍK, J. 2013. Evaluating Centroid-Moment-Tensor Uncertanty in the New Version of ISOLA Programa. Seismological Research Letters, 84(4):656-665.

WEVER, T. H. 1989. The Conrad discontinuity and the lop of the reflective lower crust - do they coincide? Tectonophysics,157:39-58.

ZAHRADNÍK, J; JANSKY, J; PLICKA, V. 2008.

Detailed waveform inversion for Moment Tensor of $\mathrm{M} \sim 4$ Events: Examples from the Corinth Gulf, Greece. Bulletin of the Seismological Society of America, 98(6):2276-2271 p. 